\title{
Cardiovascular Risk in Type 1 Diabetes Mellitus
}

\author{
Jonathan Schofield $\cdot$ Jan Ho $\cdot$ Handrean Soran
}

Received: February 17, 2019 / Published online: April 19, 2019

(C) The Author(s) 2019

\section{ABSTRACT}

Type 1 diabetes mellitus (T1DM) is associated with premature cardiovascular disease (CVD), but the underlying mechanisms remain poorly understood. The American Diabetes Association and the European Association for the Study of Diabetes recently updated their position statement on the management of type 2 diabetes mellitus (T2DM) to include additional focus on cardiovascular risk; improved management of risk factors in T1DM is also needed. There are important differences in the pathophysiology of CVD in T1DM and T2DM. Hyperglycaemia

Enhanced Digital Features To view enhanced digital features for this article go to https://doi.org/10.6084/ m9.figshare.7901828.

J. Schofield $(\bowtie)$

Manchester Diabetes Centre, Manchester Royal Infirmary, Manchester University Hospitals NHS Foundation Trust, Manchester Academic Health Science Centre, Manchester M13 9WL, UK e-mail: jschofield@doctors.org.uk

J. Schofield · J. Ho $\cdot$ H. Soran

Cardiovascular Research Group, Faculty of Biology,

Medicine and Health, University of Manchester,

Manchester M13 9WU, UK

J. Ho $\cdot$ H. Soran

Cardiovascular Trials Unit, University Department of Medicine, Manchester University Hospitals NHS Foundation Trust, Manchester Academic Health

Science Centre, Manchester M13 9WL, UK appears to have a more profound effect on cardiovascular risk in T1DM than T2DM, and other risk factors appear to cause a synergistic rather than additive effect, so achievement of treatment targets for all recognized risk factors is crucial to reducing cardiovascular risk. Here we discuss the evidence for addressing established cardiovascular risk factors, candidate biomarkers and surrogate measurements, and possible interventions.

Keywords: Cardiovascular disease; Cardiovascular risk; Type 1 diabetes mellitus

\section{Abbreviations}

ACE

ADA

Angiotensin converting enzyme

AGE

ApoAI

ApoB

ARB

ASCEND

BP

CAC

CIMT

CTCA American Diabetes Association

Advanced glycation end products

Apolipoprotein AI

Apolipoprotein B

Angiotensin receptor blocker

A Study of Cardiovascular Events in Diabetes

Blood pressure

Coronary artery calcification

Carotid intima-media thickness

Computed tomography

coronary angiography

CVD Cardiovascular disease

DCCT Diabetes Control and

Complications Trial 


\begin{tabular}{|c|c|}
\hline EASD & $\begin{array}{l}\text { European Association for the } \\
\text { Study of Diabetes }\end{array}$ \\
\hline ECG & Electrocardiogram \\
\hline EDC & $\begin{array}{l}\text { Epidemiology of Diabetes } \\
\text { Complications }\end{array}$ \\
\hline EDIC & $\begin{array}{l}\text { Epidemiology of Diabetes } \\
\text { Interventions and Complications }\end{array}$ \\
\hline GLP-1 & Glucagon like peptide-1 \\
\hline HbA1c & Glycated haemoglobin \\
\hline HDL & High-density lipoprotein \\
\hline hsCRP & $\begin{array}{l}\text { High sensitivity C-reactive } \\
\text { protein }\end{array}$ \\
\hline IMPROVE-IT & $\begin{array}{l}\text { Improved Reduction of } \\
\text { Outcomes: Vytorin Efficacy } \\
\text { International Trial }\end{array}$ \\
\hline LDL & Low-density lipoprotein \\
\hline $\operatorname{Lp}(\mathrm{a})$ & Lipoprotein (a) \\
\hline MMP & Matrix metalloproteinase \\
\hline NICE & $\begin{array}{l}\text { National Institute for Health and } \\
\text { Care Excellence }\end{array}$ \\
\hline PCSK9 & $\begin{array}{l}\text { Proprotein convertase subtilisin/ } \\
\text { kexin type } 9\end{array}$ \\
\hline RAGE & $\begin{array}{l}\text { Receptors for advanced } \\
\text { glycation end products }\end{array}$ \\
\hline REDUCE-IT & $\begin{array}{l}\text { Reduction of Cardiovascular } \\
\text { Events with Icosapent Ethyl- } \\
\text { Intervention Trial }\end{array}$ \\
\hline sdLDL & $\begin{array}{l}\text { Small dense low-density } \\
\text { lipoprotein }\end{array}$ \\
\hline SGLT-2 & Sodium-glucose cotransporter 2 \\
\hline T1DM & Type 1 diabetes mellitus \\
\hline T2DM & Type 2 diabetes mellitus \\
\hline UKPDS & $\begin{array}{l}\text { United Kingdom Prospective } \\
\text { Diabetes Study }\end{array}$ \\
\hline
\end{tabular}

\section{INTRODUCTION}

Type 1 diabetes mellitus (T1DM) is associated with an almost threefold higher mortality than the general population [1]. Premature atherosclerosis is the main driver of this excess mortality for both men and women, with cardiovascular events occurring more than a decade earlier [2]. A recent meta-analysis estimated the standardized mortality ratio attributable to cardiovascular disease (CVD) to be 5.7 for men and 11.3 for women with T1DM [3].
Importantly the relative risk does not appear to be related to disease duration. The incidence of CVD is approximately $1-2 \%$ per year even among young adults with T1DM [4]. Recent data from Sweden show up to a tenfold elevated risk of cardiovascular mortality in T1DM according to glycaemic control, and up to an eightfold increase in risk at various ages, compared with the general population [5]. By the age of 45 years, more than $70 \%$ of men and 50\% of women with T1DM have developed coronary artery calcification (CAC) [6].

Although the correlation between diabetes and CVD is well established, the underlying mechanisms remain poorly understood.

Early studies of cardiovascular mortality in T1DM suggested that risk only significantly increases after the development of nephropathy, which coincides with a marked deterioration of the lipid profile and blood pressure (BP) [7]. A standardized mortality ratio of up to 39-fold has been reported in patients with T1DM and significant renal disease [5]. While features such as the presence of nephropathy or retinopathy identify higher risk groups, the use of other biomarkers of risk and indeed the indication for enhanced treatment is often not appreciated.

The American Diabetes Association (ADA) and the European Association for the Study of Diabetes (EASD) recently updated their position statement on the management of type 2 diabetes (T2DM) in adults, to include additional focus on cardiovascular risk factor management [8]. A similar approach in T1DM seems entirely reasonable.

Improved management of traditional cardiovascular risk factors has led to remarkable improvements in survival, with a $29 \%$ reduction in the relative risk of death over a 10-year period [9], such that the overall relative risk for CVD is now 2.3 for men and 3.0 for women [10]. This relative risk was previously reported as being 3.6 in men and 7.7 in women [4]. The excess relative risk in women with T1DM is not explained by changes in known cardiovascular risk factors [11]. In contrast to the general population therefore, female sex should not be considered to offer protection against CVD [12]. It is important that clinicians recognise that 
men and women with T1DM now have a similar absolute risk of CVD [13].

This article is based on previously conducted studies and does not contain any studies with human participants or animals performed by any of the authors.

\section{ESTABLISHED RISK FACTORS}

The acceleration of atherosclerosis in T1DM is likely to result from many pathways (Fig. 1), including effects from inflammation, dyslipidaemia, hypertension and nephropathy [14]. Known risk factors seem to operate differently in T1DM, suggesting a difference in the pathophysiology of CVD [3]. The United Kingdom Prospective Diabetes Study (UKPDS) risk engine has been shown to underestimate the risk of
CVD in T1DM [15]. Risk calculator engines do not usually account for glycaemic control, the duration of diabetes or presence of microvascular complications (Fig. 2).

In an analysis of the Pittsburgh Epidemiology of Diabetes Complications (EDC) Study baseline glycated haemoglobin (HbA1c), duration of diabetes, lower insulin doses, impaired renal function, increased albumin excretion, higher diastolic BP and lipid profile were all predictive of CVD [16]. The Steno Type 1 Risk Engine for the prediction of a first cardiovascular event in T1DM includes ten risk factors: age, sex, diabetes duration and HbA1c, systolic BP, low-density lipoprotein (LDL) cholesterol, glomerular filtration rate and albuminuria, and smoking and exercise [17]. Age appears to be by far the most significant factor, followed by timeweighted mean HbA1c [18]. Development of

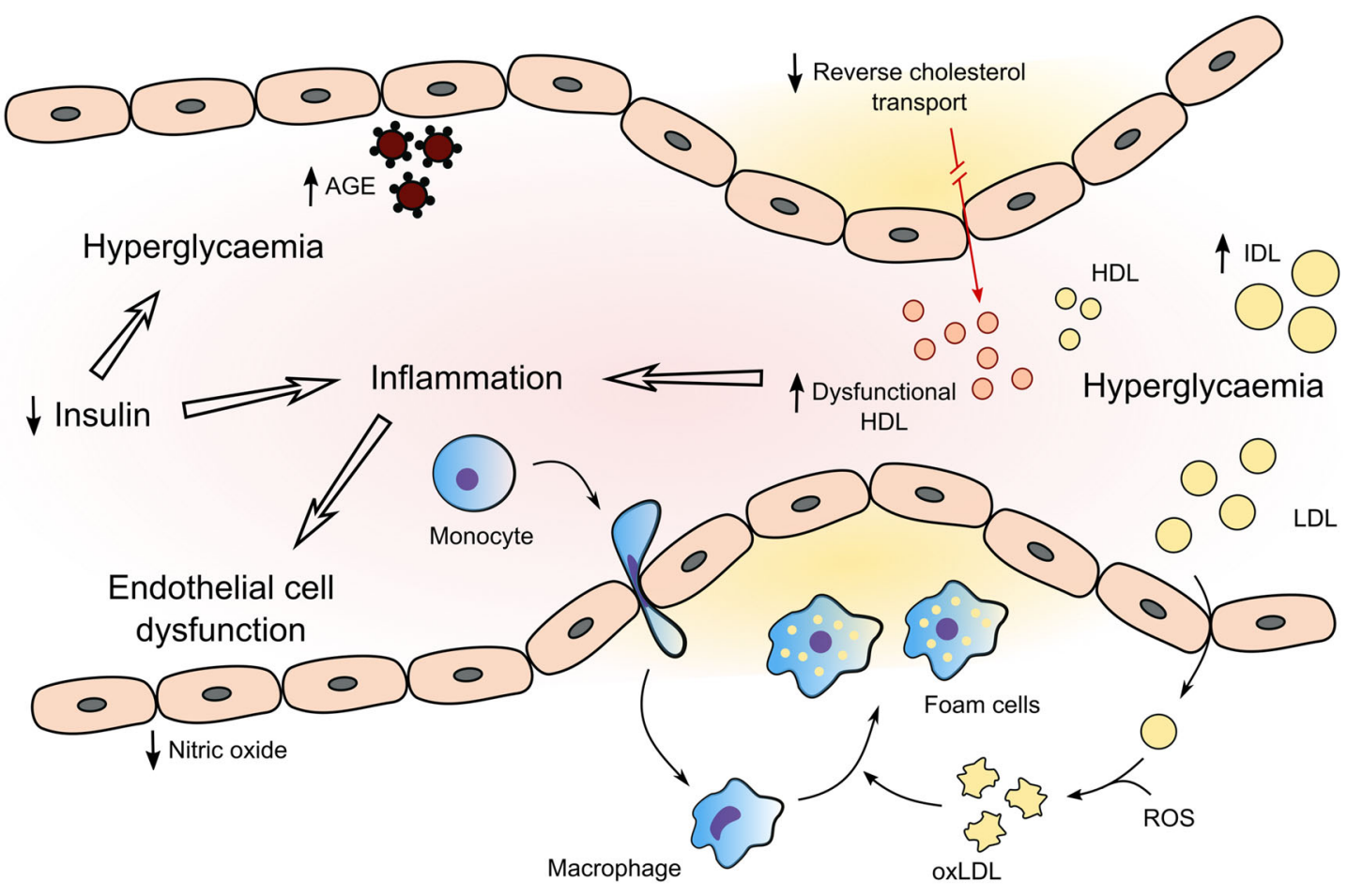

Fig. 1 Summary of mechanisms underlying cardiovascular disease in type 1 diabetes. Hyperglycaemia results in enhanced formation of AGEs and an adverse lipid profile with high levels of atherogenic IDL and dysfunctional HDL. There is a resultant impairment in reverse cholesterol transport and anti-inflammatory properties of HDL. Low insulin levels and hyperglycaemia further contribute to the systemic inflammatory process which is central to vascular endothelial dysfunction and atherosclerosis. $A G E$ advanced glycation end products, $H D L$ high-density lipoprotein, $I D L$ intermediate-density lipoprotein, $L D L$ low-density lipoprotein, oxLDL oxidised low-density lipoprotein, $R O S$ reactive oxygen species 


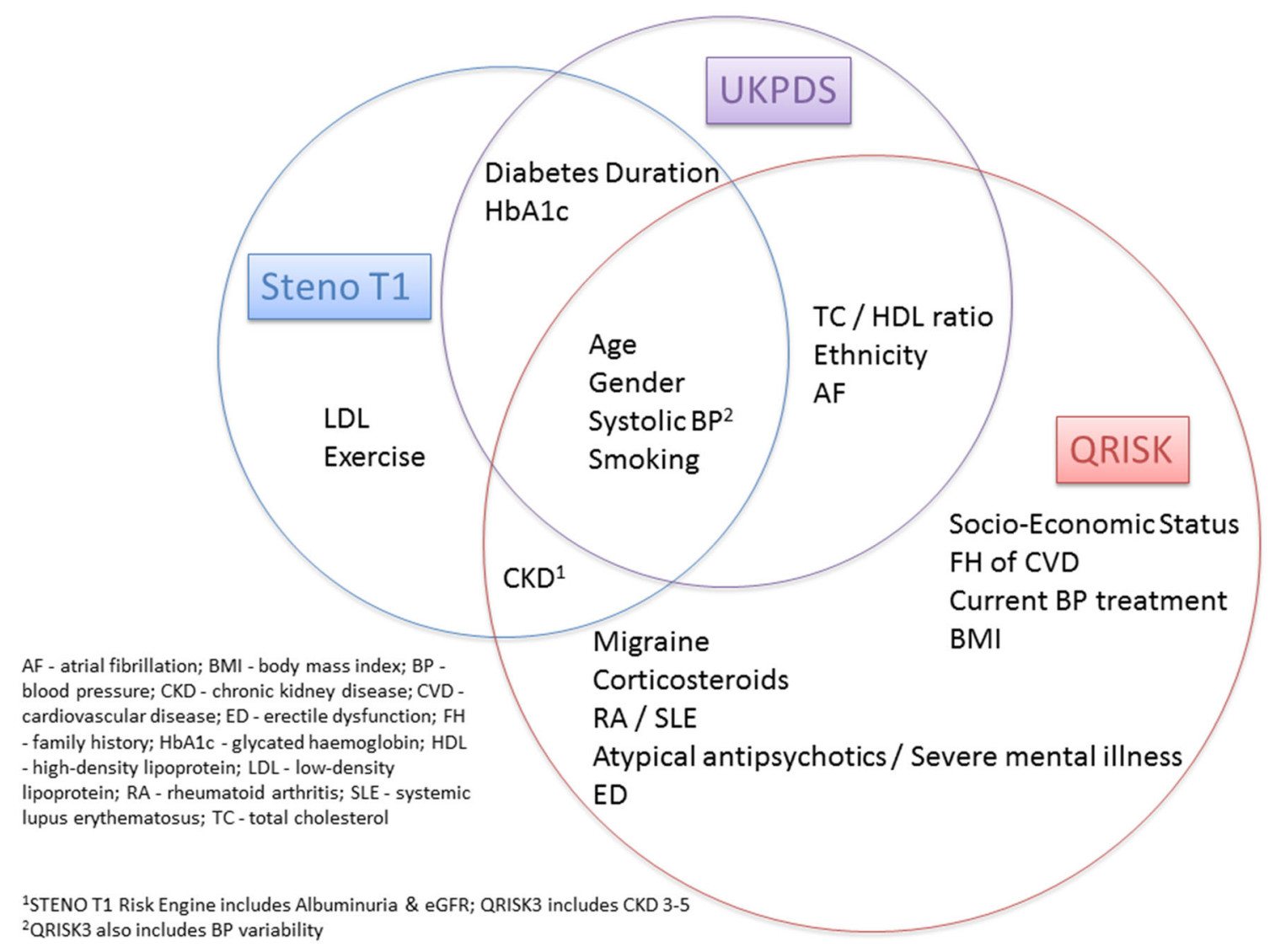

Fig. 2 Cardiovascular risk engines: Steno T1—https://steno.shinyapps.io/T1RiskEngine/; UKPDS—https://www.dtu.ox. ac.uk/riskengine/; QRISK3-https://qrisk.org/three/

T1DM before 10 years of age is associated with a 30-fold increased risk of CVD in early adulthood; women with onset of T1DM before 10 years of age have a 90 -fold increased risk of acute myocardial infarction over the same period [19].

Hyperglycaemia appears to have a more profound effect on cardiovascular risk in T1DM than T2DM. A recent study from the Swedish National Diabetes Register showed that individuals with T1DM who have an HbA1c of $52 \mathrm{mmol} / \mathrm{mol}$ or lower still have a risk of death from cardiovascular causes twice as high as the risk in the general population; the risks are several times higher among patients with higher HbA1c concentrations [5]. HbA1c may also relate more strongly to fatal rather than nonfatal CVD events [20]. The Diabetes Control and Complications Trial (DCCT) and its Epidemiology of Diabetes Interventions and
Complications (EDIC) post-randomisation follow-up demonstrated the beneficial effects of an average of 6.5 years of intensive versus conventional diabetes therapy on CVD risk [21].

The presence of diabetes mellitus in conjunction with other risk factors appears to cause a synergistic rather than additive additional risk [22]. Hyperglycaemia in animals with streptozotocin-induced diabetes mellitus results in atherosclerotic lesion formation, which can be prevented by intensive insulin therapy, while accelerated atherosclerosis develops in the setting of hypercholesterolaemia [23].

A large observational study of people with T1DM in Swedish clinical practice showed that each $1 \mathrm{mmol} / \mathrm{l}$ increase in LDL cholesterol translates into a $9 \%$ elevated risk of CVD in individuals without lipid-lowering medication, but LDL cholesterol does not appear to be a 
good marker of cardiovascular risk in primary prevention in patients with T1DM [24]. The EURODIAB Prospective Complications Study of T1DM also found that LDL cholesterol was not predictive of CVD [25]. Nevertheless, the ADA Standards of Medical Care in Diabetes suggests LDL cholesterol $\geq 2.6 \mathrm{mmol} / \mathrm{l}$ as a marker of increased cardiovascular risk [26].

Importantly, the apparently normal serum cholesterol concentrations frequently observed in T1DM hide an atherogenic lipid profile, with increased intermediate-density lipoprotein and small dense low-density lipoprotein (sdLDL), and dysfunctional high-density lipoprotein (HDL) [27]. HDL cholesterol levels are often normal or even high unless glycaemic control is poor or nephropathy has developed [28]. Hypertriglyceridaemia may also occur, and the risk associated with it is stronger than in the general population [29].

LDL particle size, its glycation and oxidation are all associated with endothelial dysfunction and CVD [30]. sdLDL penetrates the arterial wall more easily than large buoyant LDL, is more susceptible to oxidative stress, has a prolonged plasma half-life and has a reduced binding affinity for LDL receptors [31]. These characteristics would all be expected to contribute to increased atherogenicity. There is considerable evidence implicating lipid peroxidation and oxidative modification of LDL in atherosclerotic lesion development [32], but non-enzymatic glycation of LDL may be just as important. sdLDL is more readily glycated than larger more buoyant LDL both in vivo and in vitro, possibly because a higher proportion of the apolipoprotein B (apoB) molecule is exposed to glucose [33].

In risk prediction models for patients with T1DM, total cholesterol and HDL cholesterol are more important than LDL cholesterol in predicting adverse cardiovascular outcomes [34]. In a recent large observational study cardiovascular risk in T1DM was predicted by total cholesterol/HDL cholesterol, and non-HDL cholesterol but not LDL cholesterol [24]. In the INTERHEART study the non-fasting apoB/ apolipoprotein AI (apoAI) ratio was a better predictor of myocardial infarction than any single lipid or apolipoprotein concentration, or any other combination or ratio of measurements [35]. In the Finnish Diabetic Nephropathy Study a broad spectrum of lipid variables was evaluated, and the apoB/apoAI ratio was found to be the best predictor for women with normoalbuminuria and acceptable glycaemic control, whereas apoB levels were the best predictor in patients with macroalbuminuria [36].

In patients with T1DM with good glycaemic control, insulin upregulates lipoprotein lipase, increasing the production of small HDL particles [37], frequently to higher than normal HDL cholesterol levels [38]. HDL cholesterol in diabetes has thus not arisen physiologically; HDL dysfunction is suggested by the observation that these high HDL cholesterol levels do not appear to offer protection against CVD [39, 40]. A recent study in T1DM suggested that HDL cholesterol loses its protective effect above $1.3 \mathrm{mmol} / \mathrm{l}$ in women, with very high HDL cholesterol levels associated with a higher risk of CVD in both men and women [41].

A recent temporal analysis showed hypertension to be the major unaddressed risk factor for major diabetes complications [42]. The loss of female protection in diabetes may be related to less aggressive care with lower achievement of recommended risk factor levels in women than in men [43]. Diabetic nephropathy dramatically increases the risk of CVD [44]. A recent study found a similar incidence of CVD among men and women after adjustment for the higher prevalence of diabetic nephropathy in men [13].

A recent long-term follow-up of patients registered in the Swedish National Diabetes Register found no effect from improved management of established risk factors on hospitalizations for heart failure in patients with T1DM, whereas patients with T2DM had a greater event-rate reduction than their matched controls, suggesting that some processes contributing to heart failure risk are not addressed by current clinical care for patients with T1DM [9]. 


\section{CANDIDATE BIOMARKERS OF CARDIOVASCULAR RISK}

Although cardiovascular risk may not be evident from the standard lipid profile, both apoB and apolipoprotein CIII have been linked with nephropathy and atherosclerosis, and these effects may be enhanced in T1DM [45]. The concentration of dysfunctional HDL particles is increased in T1DM, and a shift in apolipoprotein $\mathrm{M}$ and its ligand sphingosine 1-phosphate between HDL particles in women with T1DM is associated with impaired anti-inflammatory effects [46].

Elevated lipoprotein (a) $[\operatorname{Lp}(\mathrm{a})]$ is an independent genetically determined causal risk factor for atherosclerotic CVD [47]. The influence of T1DM on $\mathrm{Lp}(\mathrm{a})$ is not clear, but a prospective observational study suggested that Lp(a) levels greater than $30 \mathrm{mg} / \mathrm{dl}$ might be of value in predicting cardiovascular events in patients with T1DM [48]. Interestingly, intensive treatment in the DCCT was associated with decreased $L p(a)$ as well as apoB [49].

The changes in LDL particle size and its glycation and oxidation described above are associated with endothelial dysfunction and CVD [30]. Endothelial injury and dysfunction are a common link for all cardiovascular risk factors [50]. Activation of oxidative stress by hyperglycaemia plays a major role in the pathogenesis of complications in diabetes [51]. Oxidized LDL inhibits endothelium-dependent vasorelaxation through decreased nitric oxide bioavailability [52].

Insulin itself has been associated with both protective and adverse effects on vascular endothelium, and it is worth noting that treatment with subcutaneous insulin results in higher peripheral insulin concentrations than are seen with only endogenously secreted insulin [53]. Similarly, aberrant insulin signalling promotes endothelial dysfunction through decreased endothelial nitric oxide synthase activity [54], stimulating leucocyte and platelet adhesion, thrombosis and inflammation [55]. Elevated concentrations of plasminogen activator inhibitor-1 antigen, von Willebrand factor-antigen, fibrinogen and clotting factors and lower levels of protein $\mathrm{C}$ may also contribute to CVD [56].

Hyperglycaemia induces the non-enzymatic glycation of proteins, resulting in the formation of advanced glycation end products (AGE), including the predominant carboxymethyl lysine, which interact with the arterial wall through specific receptors, including receptors for AGE (RAGE), contributing to atherosclerosis [57]. Increased AGE have been shown to be associated with rupture-prone plaques and incident $\mathrm{CVD}$ in individuals with T1DM $[58,59]$.

Cystatin $\mathrm{C}$ is well established in the assessment of renal function and nephropathy in T1DM, but recent interest has centred on its potential value in cardiovascular risk assessment [60]. Epidemiological studies show a strong association between circulating cystatin $\mathrm{C}$ and the development of CVD independent of renal function [61]. Serum uromodulin appears to have renal protective properties; higher levels also appear to be associated with reduced coronary artery calcification [62].

Recent data suggest that altered regulation of extracellular matrix remodelling by matrix metalloproteinases (MMPs) could contribute to CVD in T1DM [63]. Higher MMP-2 levels are independently associated with incident cardiovascular events in T1DM, an effect attenuated after adjustment for glomerular filtration rate [64].

Atherosclerosis is a systemic, low-grade inflammatory disease [50]. Biomarkers of inflammation may aid in predicting cardiovascular risk. Vascular endothelial dysfunction and inflammation are features of T1DM [65]. Increased glucose variability in T1DM leads to endothelial dysfunction and accelerated atherosclerosis, independently of average glucose concentrations, probably through increased oxidative stress [66]. An increase in inflammatory cytokines contributes to plaque instability, and their accumulation is believed to cause endothelial injury and altered coagulation in patients with T1DM [67].

Elevated high sensitivity C-reactive protein (hsCRP) may reflect systemic inflammation but may also directly contribute to atherosclerosis [68]. In a large meta-analysis of prospective 
studies CRP was strongly associated with the risk of CVD and ischaemic stroke in people without any history of vascular disease [69]. Higher plasma CRP concentrations correlate with markers of endothelial dysfunction in T1DM, even in the absence of CVD [70]. Cardiac autoimmunity has also recently been linked with inflammation, with cardiac autoantibodies associated with both elevated hsCRP levels and CVD outcomes in T1DM [71].

Large prospective studies have not demonstrated increased mortality related to hypoglycaemia in patients with T1DM, but a recent retrospective cohort study using the Clinical Practice Research Datalink database reported a hazard ratio for all-cause mortality of 1.98 in patients with T1DM who had experienced at least one episode of severe hypoglycaemia [1].

\section{SURROGATE MEASUREMENTS OF ATHEROSCLEROSIS: SCREENING AND DETECTION}

Diabetic retinopathy is an independent predictor of cardiovascular events and all-cause mortality in T1DM [72]. Importantly, severe forms are associated with CAC even in the absence of symptoms [73]. The significance of this association is not always appreciated.

The resting 12-lead electrocardiogram (ECG) is the most accessible test for CVD, and new ECG abnormalities were found to be common over follow-up in the EDIC study [74]. Age, HbA1c, systolic BP and smoking were reported to be independent risk factors for the development of new major ECG abnormalities. There could therefore be a role for the ECG in identifying patients with T1DM who might benefit from closer follow-up.

Carotid intima-media thickness (CIMT) is a good surrogate marker of atherosclerosis and an independent predictor of cardiovascular events [75]. CIMT is increased in people with T1DM [76]. Severity of atherosclerosis in T1DM as measured by carotid ultrasound has been correlated with age, hypertension, LDL subfractions and particle number, LDL and HDL cholesterol, apoB, smoking and retinopathy [77]. CIMT progression in the EDIC trial was associated with age, systolic BP, smoking, the LDL/HDL ratio, urinary albumin excretion rate and HbA1c [78]. Increased CIMT has also been associated with insulin resistance [79]. sdLDL has been shown to be closely associated with CIMT, and more so than other lipid parameters, including LDL, apoB, total cholesterol, HDL and apoAI levels [80].

Computed tomography coronary angiography (CTCA) is increasingly employed to detect CVD. A recent study demonstrated a high prevalence of undiagnosed obstructive coronary artery disease in patients with T1DM of long duration, with an association with mean HbA1c [81]. CTCA can also be used to generate CAC scores. Patients with T1DM with both elevated apoB and non-HDL cholesterol have greater CAC [82]. Progression of CAC is also strongly associated with $\mathrm{HbA1c}$ and glycaemic variability [83]. A recent analysis of CAC scores in patients with T1DM suggested an association of higher scores with severe hypoglycaemia [84].

\section{REDUCING CARDIOVASCULAR RISK}

Glucose-lowering therapy, statin use, BP control and lifestyle interventions including smoking cessation have improved outcomes, but individuals with T1DM continue to have a markedly elevated risk of cardiovascular events and death compared with the general population [5]. This is in contrast to T2DM, where not smoking and effective HbA1c, LDL, BP and albuminuria management are associated with little or no excess mortality compared with the general population [85].

Hyperglycaemia is well established as an independent risk factor for CVD; this risk can be reduced in patients with T1DM if strict glycaemic control can be maintained [21]. Over a mean follow-up of 28 years, the DCCT and its observational follow-up, the EDIC study, demonstrated that an average of 6.5 years of intensive diabetes therapy, resulting in a mean HbA1c of $7 \%(53 \mathrm{mmol} / \mathrm{mol})$, reduced the risk of any CVD event by 30\% compared with conventional therapy, which resulted in a mean $\mathrm{HbA} 1 \mathrm{c}$ of $9 \%$ (75 mmol/mol) [86]. Importantly, these benefits take years to manifest, but persist. 
Among people with T1DM use of insulin pump therapy is associated with lower cardiovascular mortality than treatment with multiple daily insulin injections [87]. As discussed above, this effect may be at least partially related to improved endothelial function through reduced glucose variability [88]. Hypoglycaemia is an independent risk factor for CVD, particularly among high-risk individuals, and efforts should be made to reduce events [89].

Improved glycaemic control generally has favourable effects on lipoprotein levels in diabetes, with a reduction in cholesterol and triglyceride levels through decreased circulating very-low-density lipoprotein and by increased catabolism of LDL through reduced glycation and upregulation of LDL receptors [90, 91]. A significant proportion of the cardiovascular benefit associated with intensive glucose-lowering is likely related to effects on lipoprotein metabolism rather than directly through altered glycaemia [92, 93].

The efficacy of lowering LDL cholesterol in reducing cardiovascular morbidity and mortality is well established [94]. There is strong and convincing evidence that cholesterol-lowering is at least as effective in reducing CVD in patients with diabetes as in the general population [95-97]. However, the number of people with T1DM in these studies is limited. In metaanalyses from the Cholesterol Treatment Trialists' Collaborators, only 1466 of the 18,686 people with diabetes were diagnosed with T1DM [97]. The first evidence that people with T1DM might benefit from statin therapy came from the 615 patients with T1DM in the Heart Protection Study, where simvastatin treatment was associated with a $24 \%$, albeit non-significant, event rate reduction [98]. Subsequent studies have confirmed that primary prevention with lipid-lowering medications reduces cardiovascular and all-cause mortality, CVD, stroke, coronary heart disease and acute myocardial infarction among individuals with T1DM [99].

National Institute for Health and Care Excellence (NICE) guidance advises clinicians to offer statin treatment for primary prevention to adults with T1DM who are over 40 years, have had diabetes for more than 10 years, or have established nephropathy or other cardiovascular risk factors [100]. ADA guidelines recommend consideration of statin therapy of moderate intensity, in addition to lifestyle therapy, for all patients with T1DM aged 40 years or older; in younger patients, treatment should be considered if the cardiovascular risk is deemed to be elevated because of the presence of cardiovascular risk factors and a high-dose statin recommended in the case of overt CVD [26].

The Improved Reduction of Outcomes: Vytorin Efficacy International Trial (IMPROVEIT) found value in the use of ezetimibe to further reduce LDL-cholesterol, with a greater cardiovascular benefit among patients with diabetes mellitus [101]. Patients with T1DM would be expected to draw as much benefit from LDL-lowering with proprotein convertase subtilisin/kexin type 9 (PCSK9) inhibitors as the general population [102].

Omega-3 (n-3) fatty acid supplementation does not appear to have any cardiovascular benefit in patients with diabetes [103], although the Reduction of Cardiovascular Events with Icosapent Ethyl-Intervention Trial (REDUCE-IT) recently demonstrated that higher doses of formulations with higher ratios of eicosapentanoic acid to docosahexaenoic acid do reduce cardiovascular events in patients with elevated triglyceride levels [104].

NICE recommends interventions to achieve a BP of $135 / 85 \mathrm{mmHg}$ unless albuminuria or features of the metabolic syndrome are also present, in which case the target should be $130 / 80 \mathrm{mmHg}$. First-line therapy should be with angiotensin converting enzyme (ACE) inhibitors or angiotensin receptor blockers (ARBs) [105]. The ADA recommends that most patients with diabetes and hypertension should be treated to a systolic BP goal of $<140 \mathrm{mmHg}$ and a diastolic BP goal of $<90 \mathrm{mmHg}$, with the same target of $130 / 80 \mathrm{mmHg}$ for individuals at high risk of CVD. Initial treatment is recommended with any antihypertensive demonstrated to reduce cardiovascular events in patients with diabetes: ACE inhibitors, ARBs, thiazide-like diuretics or dihydropyridine calcium channel blockers [26]. Both micro- or macroalbuminuria and impaired glomerular 
filtration rate are independent risk factors for CVD [106]. For patients with albuminuria, initial treatment should include an ACE inhibitor or ARB [107].

Current recommendations for blood pressure and lipid modification in T1DM are shown in Table 1 [26, 100, 105, 108, 109].
Increased body mass index has not been established as a strong risk factor for CVD or mortality in T1DM, but 'excessive' weight gain during the DCCT was associated with a delayed increase in cardiovascular events, which offset the benefit derived from intensive glycaemic control [110]. Although no clinical trials have

Table 1 Current recommendations for blood pressure and lipid modification in T1DM

\author{
American Diabetes Association (ADA) \\ 2018 \\ European Society of Cardiology (ESC) \\ 2016
}

Joint British Societies (JBS) 2014

National Institute for Health and Care Excellence (NICE) 2014

Blood pressure management

ADA 2018

ESC 2016

JBS 2014

NICE 2015
Offer statin treatment to:

All patients aged $>40$ years

Patients aged $<40$ years with additional risk factors

Offer statin treatment to:

All patients $>40$ years unless short duration of diabetes $\&$ no other risk factors

Younger patients with multiple risk factors or evidence of end organ damage (albuminuria, low eGFR, proliferative retinopathy or neuropathy)

Offer statin treatment to:

All patients aged $\geq 50$ years

Patients aged $40-50$ years unless duration of diabetes $<5$ years

Patients aged 30-40 years with duration of diabetes $>20$ years/HbAlc $>75 \mathrm{mmol} / \mathrm{mol} /$ persistent albuminuria $>30 \mathrm{mg} /$ day or eGFR $<60 \mathrm{ml} /$ $\mathrm{min} /$ proliferative retinopathy/treated hypertension/current smoking/ autonomic neuropathy/total cholesterol $>5 \mathrm{mmol} / \mathrm{l}$ with reduced $\mathrm{HDL} /$ central obesity/family history of premature CVD

Patients aged $18-30$ years if persistent albuminuria

Offer statin treatment to:

All patients $>40$ years

Patients with diabetes $>10$ years/established nephropathy/other CVD risk factors

\section{Recommendation in type 1 diabetes}

Intervene at 140/90 $\mathrm{mmHg}$; a target of $130 / 80 \mathrm{mmHg}$ may be appropriate for individuals at higher risk

Target $130 / 80 \mathrm{mmHg}$, or $120 / 75-80 \mathrm{mmHg}$ in patients $<40$ years with persistent microalbuminuria

Maintain at 130/80 $\mathrm{mmHg}$, with consideration of lower values in patients aged $<40$ years with persistent microalbuminuria

Intervene at $135 / 85 \mathrm{mmHg}$, or $130 / 80 \mathrm{mmHg}$ with albuminuria or features of metabolic syndrome 
demonstrated that physical activity reduces cardiovascular events in T1DM, improvements in glycaemia, dyslipidaemia, BP and endothelial dysfunction have all been reported [111, 112]. Efforts should therefore be made to promote and reinforce lifestyle management recommendations. This should include consideration as to whether hypoglycaemia, or fear of hypoglycaemia, presents a barrier to implementing these measures [22].

Low carbohydrate diets are frequently employed with the aim of reducing glucose excursions, but if energy intake is unchanged, protein and fat intake will increase. Contrary to expectations, established cardiovascular risk factors do not seem to be affected by this diet [113]. Higher dietary fibre consumption may, however, be protective against CVD [114]. Adherence to dietary recommendations has also been associated with reductions in low-grade inflammation [115].

Anti-platelet agents are currently only recommended as a secondary prevention strategy but may be considered for primary prevention in individuals with T1DM who have at least one additional major risk factor [26]. ASCEND (A Study of Cardiovascular Events in Diabetes) reported that daily aspirin use over 7.4 years resulted in significantly fewer serious vascular events but also an increased risk of major bleeding, such that 91 patients would need to be treated to avoid a serious vascular event, and 112 to cause major bleeding [116].

Advances in revascularization and increased use of glucose-monitoring systems may also have played a role in reducing cardiovascular events [87], but a recent prospective observational study of 33,333 patients with T1DM and 166,529 matched controls showed that patients with T1DM with BP, LDL-cholesterol, smoking, albuminuria and $\mathrm{HbA1c}$ at target continue to display a clear excess risk for acute myocardial infarction and heart failure compared with the general population [117]. Importantly, each risk factor not at target is associated with a steep increase in excess risk. Thus, achievement of treatment targets for all recognized risk factors is crucial to reducing cardiovascular risk in T1DM.

Further reduction in cardiovascular events in T1DM might be achieved through the use of glucose-lowering medications associated with cardiovascular benefits in T2DM. Metformin can be added to insulin therapy in overweight or obese individuals with T1DM to reduce insulin requirements [26]. Metformin might also have direct effects on atherosclerosis progression, but recent data and current guidelines do not support its use to improve glycaemic control [118].

Glucagon like peptide-1 (GLP-1) analogues have shown promise in their ability to both reduce $\mathrm{HbA1c}$ and weight in patients with T1DM [119]. Rates of symptomatic hypoglycaemia and hyperglycaemia with ketosis may however be increased. An amylin analogue, pramlintide, is approved for use in the treatment of T1DM in the USA. Pramlintide also appears to improve glycaemic control and reduce weight in patients with T1DM [120]. Furthermore, pramlintide use is associated with a decrease in postprandial hyperglycaemia, which would be expected to offer cardiovascular benefit through reduced oxidative stress and improved endothelial function [121].

Sodium-glucose cotransporter 2 (SGLT-2) inhibitors in particular might prove useful as an adjunct therapy to insulin. The mechanistic effects linked to the cardiovascular benefits of SGLT-2 inhibitors in T2DM have also been documented in T1DM [122]. Dual SGLT-1/2 inhibition is associated with a greater reduction in postprandial glucose excursions [123]. A recent meta-analysis reported reductions in both bolus and basal insulin doses when an SGLT-2 inhibitor was added to insulin monotherapy [124]. Hypoglycaemia rates are not increased but there is an associated increased risk of diabetic ketoacidosis. Using the lowest available dose of SGLT inhibitor may reduce this risk.

Beyond the use of anti-platelets, glucose, BP and lipid-lowering medications, there may be scope to address residual cardiovascular risk through novel therapeutics. Whether targeting inflammation might reduce cardiovascular event rates is under investigation in multiple large-scale clinical trials including promising results from targeting interleukin-1 $\beta$ with the monoclonal antibody canakinumab [125]. 


\section{CONCLUSION}

Type 1 diabetes mellitus is associated with an almost threefold higher mortality than the general population. Although the correlation between T1DM and CVD is well established, the underlying mechanisms remain poorly understood and the need for enhanced treatment is often not appreciated. It is also important that clinicians recognise that men and women with T1DM have a similar absolute risk of CVD. Glucose-lowering therapy, statin use, BP control and lifestyle interventions have improved outcomes, but individuals with T1DM continue to have a markedly elevated risk of cardiovascular events and death compared with the general population. There is therefore scope to address this residual risk through improved identification of 'at risk' individuals, and novel interventions.

\section{ACKNOWLEDGEMENTS}

Funding. No funding or sponsorship was received for the publication of this article.

Authorship. All named authors declare that they have no conflict of interest, meet the International Committee of Medical Journal Editors criteria for authorship for this article, take responsibility for the integrity of the work as a whole, and have given their approval for this version to be published.

Disclosures. Jonathan Schofield, Jan Ho and Handrean Soran have nothing to disclose.

Compliance with Ethics Guidelines. This article is based on previously conducted studies and does not contain any studies with human participants or animals performed by any of the authors.

Open Access. This article is distributed under the terms of the Creative Commons Attribution-NonCommercial 4.0 International License (http://creativecommons.org/licenses/ by-nc/4.0/), which permits any noncommercial use, distribution, and reproduction in any medium, provided you give appropriate credit to the original author(s) and the source, provide a link to the Creative Commons license, and indicate if changes were made.

\section{REFERENCES}

1. Khunti K, Davies M, Majeed A, Thorsted BL, Wolden ML, Paul SK. Hypoglycemia and risk of cardiovascular disease and all-cause mortality in insulintreated people with type 1 and type 2 diabetes: a cohort study. Diabetes Care. 2015;38(2):316-22. https://doi.org/10.2337/dc14-0920.

2. Secrest AM, Becker DJ, Kelsey SF, Laporte RE, Orchard TJ. Cause-specific mortality trends in a large population-based cohort with long-standing childhood-onset type 1 diabetes. Diabetes. 2010;59(12):3216-22. https://doi.org/10.2337/ db10-0862.

3. Huxley RR, Peters SA, Mishra GD, Woodward M. Risk of all-cause mortality and vascular events in women versus men with type 1 diabetes: a systematic review and meta-analysis. Lancet Diabetes Endocrinol. 2015;3(3):198-206. https://doi.org/10. 1016/S2213-8587(14)70248-7.

4. Soedamah-Muthu SS, Fuller JH, Mulnier HE, Raleigh VS, Lawrenson RA, Colhoun HM. High risk of cardiovascular disease in patients with type 1 diabetes in the U.K.: a cohort study using the general practice research database. Diabetes Care. 2006;29(4): 798-804.

5. Lind M, Svensson AM, Kosiborod M, et al. Glycemic control and excess mortality in type 1 diabetes. N Engl J Med. 2014;371(21):1972-82. https://doi. org/10.1056/NEJMoa1408214.

6. Costacou T, Edmundowicz D, Prince C, Conway B, Orchard TJ. Progression of coronary artery calcium in type 1 diabetes mellitus. Am J Cardiol. 2007; 100(10):1543-7. https://doi.org/10.1016/j.amjcard. 2007.06.050.

7. Winocour PH, Durrington PN, Ishola M, Anderson DC, Cohen H. Influence of proteinuria on vascular disease, blood pressure, and lipoproteins in insulin dependent diabetes mellitus. Br Med J (Clin Res Ed). 1987;294(6588):1648-51.

8. Davies MJ, D'Alessio DA, Fradkin J, et al. Management of hyperglycaemia in type 2 diabetes, 2018. A consensus report by the American Diabetes 
Association (ADA) and the European Association for the Study of Diabetes (EASD). Diabetologia. 2018. https://doi.org/10.1007/s00125-018-4729-5.

9. Rawshani A, Rawshani A, Gudbjornsdottir S. Mortality and cardiovascular disease in type 1 and type 2 diabetes. N Engl J Med. 2017;377(3):300-1. https://doi.org/10.1056/NEJMc1706292.

10. Livingstone SJ, Looker HC, Hothersall EJ, et al. Risk of cardiovascular disease and total mortality in adults with type 1 diabetes: Scottish registry linkage study. PLoS Med. 2012;9(10):e1001321. https://doi. org/10.1371/journal.pmed.1001321.

11. Colhoun HM, Rubens MB, Underwood SR, Fuller $\mathrm{JH}$. The effect of type 1 diabetes mellitus on the gender difference in coronary artery calcification. J Am Coll Cardiol. 2000;36(7):2160-7.

12. Dabelea D, Kinney G, Snell-Bergeon JK, et al. Effect of type 1 diabetes on the gender difference in coronary artery calcification: a role for insulin resistance? The Coronary Artery Calcification in Type 1 Diabetes (CACTI) Study. Diabetes. 2003; 52(11):2833-9.

13. Harjutsalo V, Thomas MC, Forsblom C, Groop PH, FinnDiane Study Group. Risk of coronary artery disease and stroke according to sex and presence of diabetic nephropathy in type 1 diabetes. Diabetes Obes Metab. 2018. https://doi.org/10.1111/dom. 13456.

14. Orchard TJ, Costacou T, Kretowski A, Nesto RW. Type 1 diabetes and coronary artery disease. Diabetes Care. 2006;29(11):2528-38. https://doi.org/ $10.2337 / \mathrm{dc} 06-1161$

15. Zgibor JC, Piatt GA, Ruppert K, Orchard TJ, Roberts MS. Deficiencies of cardiovascular risk prediction models for type 1 diabetes. Diabetes Care. 2006; 29(8):1860-5. https://doi.org/10.2337/dc06-0290.

16. Conway B, Costacou T, Orchard T. Is glycaemia or insulin dose the stronger risk factor for coronary artery disease in type 1 diabetes? Diab Vasc Dis Res. 2009;6(4):223-30. https://doi.org/10.1177/1479164 109336041 .

17. Vistisen D, Andersen GS, Hansen CS, et al. Prediction of first cardiovascular disease event in type 1 diabetes mellitus: the Steno Type 1 Risk Engine. Circulation. 2016;133(11):1058-66. https://doi.org/ 10.1161/CIRCULATIONAHA.115.018844.

18. The Diabetes Control and Complications Trial/Epidemiology of Diabetes Interventions and Complications Research Group. Risk factors for cardiovascular disease in type 1 diabetes. Diabetes. 2016;65(5):1370-9. https://doi.org/10.2337/db151517.
19. Rawshani A, Sattar N, Franzen S, et al. Excess mortality and cardiovascular disease in young adults with type 1 diabetes in relation to age at onset: a nationwide, register-based cohort study. Lancet. 2018;392(10146):477-86. https://doi.org/10.1016/ S0140-6736(18)31506-X.

20. de Ferranti SD, de Boer IH, Fonseca V, et al. Type 1 diabetes mellitus and cardiovascular disease: a scientific statement from the American Heart Association and American Diabetes Association. Diabetes Care. 2014;37(10):2843-63. https://doi.org/10. 2337/dc14-1720.

21. Nathan DM, Cleary PA, Backlund JY, et al. Intensive diabetes treatment and cardiovascular disease in patients with type 1 diabetes. $\mathrm{N}$ Engl J Med. 2005;353(25):2643-53. https://doi.org/10.1056/ NEJMoa052187.

22. Low Wang CC, Hess CN, Hiatt WR, Goldfine AB. Clinical update: cardiovascular disease in diabetes mellitus: atherosclerotic cardiovascular disease and heart failure in type 2 diabetes mellitus-mechanisms, management, and clinical considerations. Circulation. 2016;133(24):2459-502. https://doi. org/10.1161/CIRCULATIONAHA.116.022194.

23. Renard CB, Kramer F, Johansson F, et al. Diabetes and diabetes-associated lipid abnormalities have distinct effects on initiation and progression of atherosclerotic lesions. J Clin Investig. 2004; 114(5):659-68. https://doi.org/10.1172/JCI17867.

24. Hero C, Svensson AM, Gidlund P, Gudbjornsdottir $\mathrm{S}$, Eliasson B, Eeg-Olofsson K. LDL cholesterol is not a good marker of cardiovascular risk in type 1 diabetes. Diabet Med. 2016;33(3):316-23. https://doi. org/10.1111/dme.13007.

25. Soedamah-Muthu SS, Chaturvedi N, Toeller M, et al. Risk factors for coronary heart disease in type 1 diabetic patients in Europe: the EURODIAB Prospective Complications Study. Diabetes Care. 2004;27(2):530-7.

26. Professional Practice Committee. Standards of medical care in diabetes-2018. Diabetes Care. 2018;41(Suppl 1):S3. https://doi.org/10.2337/dc18Sppc01.

27. Jenkins AJ, Best JD, Klein RL, Lyons TJ. Lipoproteins, glycoxidation and diabetic angiopathy. Diabetes Metab Res Rev. 2004;20(5):349-68. https:// doi.org/10.1002/dmrr.491.

28. Dean JD, Durrington PN. Treatment of dyslipoproteinaemia in diabetes mellitus. Diabet Med. 1996;13(4):297-312. https://doi.org/10.1002/ (SICI)1096-9136(199604)13:4\%3c297:AID-DIA82\% 3e3.0.CO;2-Q. 
29. Stamler J, Vaccaro O, Neaton JD, Wentworth D. Diabetes, other risk factors, and 12-yr cardiovascular mortality for men screened in the Multiple Risk Factor Intervention Trial. Diabetes Care. 1993;16(2):434-44.

30. Taskinen MR. LDL-cholesterol, HDL-cholesterol or triglycerides-which is the culprit? Diabetes Res Clin Pract. 2003;61(Suppl 1):S19-26.

31. Berneis KK, Krauss RM. Metabolic origins and clinical significance of LDL heterogeneity. J Lipid Res. 2002;43(9):1363-79.

32. Steinbrecher UP, Zhang HF, Lougheed M. Role of oxidatively modified LDL in atherosclerosis. Free Radic Biol Med. 1990;9(2):155-68.

33. Soran H, Durrington PN. Susceptibility of LDL and its subfractions to glycation. Curr Opin Lipidol. 2011;22(4):254-61. https://doi.org/10.1097/MOL. Ob013e328348a43f.

34. Soedamah-Muthu SS, Vergouwe Y, Costacou T, et al. Predicting major outcomes in type 1 diabetes: a model development and validation study. Diabetologia. 2014;57(11):2304-14. https://doi.org/10. 1007/s00125-014-3358-X.

35. McQueen MJ, Hawken S, Wang X, et al. Lipids, lipoproteins, and apolipoproteins as risk markers of myocardial infarction in 52 countries (the INTERHEART study): a case-control study. Lancet. 2008;372(9634):224-33. https://doi.org/10.1016/ S0140-6736(08)61076-4.

36. Tolonen N, Forsblom C, Makinen VP, et al. Different lipid variables predict incident coronary artery disease in patients with type 1 diabetes with or without diabetic nephropathy: the FinnDiane study. Diabetes Care. 2014;37(8):2374-82. https:// doi.org/10.2337/dc13-2873.

37. Durrington PN. Serum high density lipoprotein cholesterol subfractions in type I (insulin-dependent) diabetes mellitus. Clin Chim Acta. 1982;120(1):21-8.

38. Durrington PN. Serum high density lipoprotein cholesterol in diabetes mellitus: an analysis of factors which influence its concentration. Clin Chim Acta. 1980;104(1):11-23.

39. Smith JD. Dysfunctional HDL as a diagnostic and therapeutic target. Arterioscler Thromb Vasc Biol. 2010;30(2):151-5. ATVBAHA.108.179226.

40. Schofield JD, France M, Ammori B, Liu Y, Soran H. High-density lipoprotein cholesterol raising: does it matter? Curr Opin Cardiol. 2013;28(4):464-74. https://doi.org/10.1097/HCO.0b013e328362210d.
41. Costacou T, Evans RW, Orchard TJ. High-density lipoprotein cholesterol in diabetes: is higher always better? J Clin Lipidol. 2011;5(5):387-94. https://doi. org/10.1016/j.jacl.2011.06.011.

42. Miller RG, Secrest AM, Ellis D, Becker DJ, Orchard TJ. Changing impact of modifiable risk factors on the incidence of major outcomes of type 1 diabetes: the Pittsburgh Epidemiology of Diabetes Complications Study. Diabetes Care. 2013;36(12):3999-4006. https://doi.org/10.2337/ dc13-1142.

43. Larkin ME, Backlund JY, Cleary P, et al. Disparity in management of diabetes and coronary heart disease risk factors by sex in DCCT/EDIC. Diabet Med. 2010;27(4):451-8. https://doi.org/10.1111/j.14645491.2010.02972.x.

44. Borch-Johnsen K, Kreiner S. Proteinuria: value as predictor of cardiovascular mortality in insulin dependent diabetes mellitus. Br Med J (Clin Res Ed). 1987;294(6588):1651-4.

45. Jenkins AJ, Yu J, Alaupovic P, et al. Apolipoproteindefined lipoproteins and apolipoproteins: associations with abnormal albuminuria in type 1 diabetes in the Diabetes Control and Complications Trial/ Epidemiology of Diabetes Interventions and Complications Cohort. J Diabetes Complicat. 2013;27(5):447-53. https://doi.org/10.1016/j. jdiacomp.2013.06.002.

46. Frej C, Mendez AJ, Ruiz M, et al. A shift in ApoM/ S1P between HDL-particles in women with type 1 diabetes mellitus is associated with impaired antiinflammatory effects of the ApoM/S1P complex. Arterioscler Thromb Vasc Biol. 2017;37(6): 1194-205. https://doi.org/10.1161/ATVBAHA.117. 309275.

47. Kamstrup PR, Tybjaerg-Hansen A, Steffensen R, Nordestgaard BG. Genetically elevated lipoprotein(a) and increased risk of myocardial infarction. JAMA. 2009;301(22):2331-9. https://doi.org/10. 1001/jama.2009.801.

48. Kollerits B, Auinger M, Reisig V, et al. Lipoprotein(a) as a predictor of cardiovascular disease in a prospectively followed cohort of patients with type 1 diabetes. Diabetes Care. 2006;29(7):1661-3. https://doi.org/10.2337/dc06-0546.

49. Purnell JQ, Marcovina SM, Hokanson JE, et al. Levels of lipoprotein(a), apolipoprotein B, and lipoprotein cholesterol distribution in IDDM. Results from follow-up in the Diabetes Control and Complications Trial. Diabetes. 1995;44(10): 1218-26.

50. Libby P, Ridker PM, Hansson GK. Progress and challenges in translating the biology of 
atherosclerosis. Nature. 2011;473(7347):317-25. https://doi.org/10.1038/nature10146.

51. Brownlee M. The pathobiology of diabetic complications: a unifying mechanism. Diabetes. 2005;54(6):1615-25.

52. Deckert V, Brunet A, Lantoine F, et al. Inhibition by cholesterol oxides of NO release from human vascular endothelial cells. Arterioscler Thromb Vasc Biol. 1998;18(7):1054-60.

53. Muis MJ, Bots ML, Grobbee DE, Stolk RP. Insulin treatment and cardiovascular disease; friend or foe? A point of view. Diabet Med. 2005;22(2):118-26. https://doi.org/10.1111/j.1464-5491.2004.01416.x.

54. Muniyappa R, Montagnani M, Koh KK, Quon MJ. Cardiovascular actions of insulin. Endocr Rev. 2007;28(5):463-91. https://doi.org/10.1210/er. 2007-0006.

55. Potenza MA, Addabbo F, Montagnani M. Vascular actions of insulin with implications for endothelial dysfunction. Am J Physiol Endocrinol Metab. 2009;297(3):E568-77. https://doi.org/10.1152/ ajpendo.00297.2009.

56. Kyrgios I, Maggana I, Giza S, et al. Suboptimal glycaemic control enhances the risk of impaired prothrombotic state in youths with type 1 diabetes mellitus. Diabetes Vasc Dis Res. 2014;11(3):208-16. https://doi.org/10.1177/1479164114528821.

57. Negre-Salvayre A, Salvayre R, Auge N, Pamplona R, Portero-Otin M. Hyperglycemia and glycation in diabetic complications. Antioxid Redox Signal. 2009;11(12):3071-109. https://doi.org/10.1089/ ARS.2009.2484.

58. van Eupen MG, Schram MT, Colhoun HM, Scheijen JL, Stehouwer CD, Schalkwijk CG. Plasma levels of advanced glycation endproducts are associated with type 1 diabetes and coronary artery calcification. Cardiovasc Diabetol. 2013;12:149. https://doi.org/ 10.1186/1475-2840-12-149.

59. Hanssen NM, Wouters K, Huijberts MS, et al. Higher levels of advanced glycation endproducts in human carotid atherosclerotic plaques are associated with a rupture-prone phenotype. Eur Heart J. 2014;35(17):1137-46. https://doi.org/10.1093/ eurheartj/eht 402 .

60. Maahs DM, Snell-Bergeon JK, Hokanson JE, et al. Relationship between cystatin $\mathrm{C}$ and coronary artery atherosclerosis progression differs by type 1 diabetes. Diabetes Technol Ther. 2010;12(1):25-33. https://doi.org/10.1089/dia.2009.0086.

61. van der Laan SW, Fall T, Soumare A, et al. Cystatin $\mathrm{C}$ and cardiovascular disease: a Mendelian randomization study. J Am Coll Cardiol. 2016;68(9):934-45. https://doi.org/10.1016/j.jacc. 2016.05.092.

62. Bjornstad P, Wiromrat P, Johnson RJ, et al. Serum uromodulin predicts less coronary artery calcification and diabetic kidney disease over 12 years in adults with type 1 diabetes: the CACTI study. Diabetes Care. 2018. https://doi.org/10.2337/dc181527.

63. Peeters SA, Engelen L, Buijs J, et al. Plasma levels of matrix metalloproteinase-2, $-3,-10$, and tissue inhibitor of metalloproteinase- 1 are associated with vascular complications in patients with type 1 diabetes: the EURODIAB Prospective Complications Study. Cardiovasc Diabetol. 2015;14:31. https://doi. org/10.1186/s12933-015-0195-2.

64. Peeters SA, Engelen L, Buijs J, et al. Plasma matrix metalloproteinases are associated with incident cardiovascular disease and all-cause mortality in patients with type 1 diabetes: a 12-year follow-up study. Cardiovasc Diabetol. 2017;16(1):55. https:// doi.org/10.1186/s12933-017-0539-1.

65. Ferreira I, Hovind P, Schalkwijk CG, Parving HH, Stehouwer CDA, Rossing P. Biomarkers of inflammation and endothelial dysfunction as predictors of pulse pressure and incident hypertension in type 1 diabetes: a 20 year life-course study in an inception cohort. Diabetologia. 2018;61(1):231-41. https:// doi.org/10.1007/s00125-017-4470-5.

66. Hoffman RP, Dye AS, Huang H, Bauer JA. Glycemic variability predicts inflammation in adolescents with type 1 diabetes. J Pediatr Endocrinol Metab. 2016;29(10):1129-33. https://doi.org/10.1515/ jpem-2016-0139.

67. Desouza CV, Bolli GB, Fonseca V. Hypoglycemia, diabetes, and cardiovascular events. Diabetes Care. 2010;33(6):1389-94. https://doi.org/10.2337/dc092082.

68. Verma S, Wang $\mathrm{CH}$, Li SH, et al. A self-fulfilling prophecy: C-reactive protein attenuates nitric oxide production and inhibits angiogenesis. Circulation. 2002;106(8):913-9.

69. Emerging Risk Factors Consortium, Kaptoge S, Di Angelantonio E, et al. C-reactive protein concentration and risk of coronary heart disease, stroke, and mortality: an individual participant metaanalysis. Lancet. 2010;375(9709):132-40. https:// doi.org/10.1016/s0140-6736(09)61717-7.

70. Schalkwijk CG, Poland DC, van Dijk W, et al. Plasma concentration of C-reactive protein is increased in type I diabetic patients without clinical macroangiopathy and correlates with markers of endothelial dysfunction: evidence for chronic 
inflammation. Diabetologia. 1999;42(3):351-7. https://doi.org/10.1007/s001250051162.

71. Sousa GR, Pober D, Galderisi A, et al. Glycemic control, cardiac autoimmunity, and long-term risk of cardiovascular disease in type 1 diabetes mellitus: a DCCT/EDIC cohort-based study. Circulation. 2018. https://doi.org/10.1161/circulationaha.118. 036068 .

72. Kramer CK, Rodrigues TC, Canani LH, Gross JL, Azevedo MJ. Diabetic retinopathy predicts all-cause mortality and cardiovascular events in both type 1 and 2 diabetes: meta-analysis of observational studies. Diabetes Care. 2011;34(5):1238-44. https:// doi.org/10.2337/dc11-0079.

73. Almeida FK, Esteves JF, Gross JL, Biavatti K, Rodrigues TC. Severe forms of retinopathy predict the presence of subclinical atherosclerosis in type 1 diabetes subjects. Arq Bras Cardiol. 2011; 97(4):346-9.

74. Soliman EZ, Backlund JY, Bebu I, et al. Progression of electrocardiographic abnormalities in type 1 diabetes during 16 years of follow-up: the Epidemiology of Diabetes Interventions and Complications (EDIC) Study. J Am Heart Assoc. 2016;5(3):e002882. https:// doi.org/10.1161/JAHA.115.002882.

75. O'Leary DH, Polak JF, Kronmal RA, Manolio TA, Burke GL, Wolfson SK Jr. Carotid-artery intima and media thickness as a risk factor for myocardial infarction and stroke in older adults. Cardiovascular Health Study Collaborative Research Group. N Engl J Med. 1999;340(1):14-22. https://doi.org/10.1056/ nejm199901073400103.

76. Yamasaki Y, Kawamori R, Matsushima H, et al. Atherosclerosis in carotid artery of young IDDM patients monitored by ultrasound high-resolution B-mode imaging. Diabetes. 1994;43(5):634-9.

77. Lyons TJ, Jenkins AJ, Zheng D, et al. Nuclear magnetic resonance-determined lipoprotein subclass profile in the DCCT/EDIC cohort: associations with carotid intima-media thickness. Diabet Med. 2006;23(9):955-66. https://doi.org/10.1111/j.14645491.2006.01905.x.

78. Nathan DM, Lachin J, Cleary $P$, et al. Intensive diabetes therapy and carotid intima-media thickness in type 1 diabetes mellitus. $\mathrm{N}$ Engl J Med. 2003;348(23):2294-303. https://doi.org/10.1056/ NEJMoa022314.

79. Rathsman B, Rosfors S, Sjoholm A, Nystrom T. Early signs of atherosclerosis are associated with insulin resistance in non-obese adolescent and young adults with type 1 diabetes. Cardiovasc Diabetol. 2012;11:145. https://doi.org/10.1186/1475-2840$11-145$.
80. Shoji T, Hatsuda S, Tsuchikura S, et al. Small dense low-density lipoprotein cholesterol concentration and carotid atherosclerosis. Atherosclerosis. 2009;202(2):582-8. https://doi.org/10.1016/j. atherosclerosis.2008.04.042.

81. Holte KB, Svanteson M, Hanssen KF, Haig Y, Solheim S, Berg TJ. Undiagnosed coronary artery disease in long-term type 1 diabetes. The Dialong study. J Diabetes Complicat. 2019. https://doi.org/ 10.1016/j.jdiacomp.2019.01.006.

82. Bjornstad P, Eckel RH, Pyle L, Rewers M, Maahs DM, Snell-Bergeon JK. Relation of combined non-highdensity lipoprotein cholesterol and apolipoprotein $\mathrm{B}$ with atherosclerosis in adults with type 1 diabetes mellitus. Am J Cardiol. 2015;116(7):1057-62. https://doi.org/10.1016/j.amjcard.2015.07.020.

83. Snell-Bergeon JK, Roman R, Rodbard D, et al. Glycaemic variability is associated with coronary artery calcium in men with type 1 diabetes: the Coronary Artery Calcification in Type 1 Diabetes study. Diabet Med. 2010;27(12):1436-42. https://doi.org/10. 1111/j.1464-5491.2010.03127.x.

84. Fahrmann ER, Adkins L, Loader CJ, et al. Severe hypoglycemia and coronary artery calcification during the Diabetes Control and Complications Trial/Epidemiology of Diabetes Interventions and Complications (DCCT/EDIC) Study. Diabetes Res Clin Pract. 2015;107(2):280-9. https://doi.org/10. 1016/j.diabres.2014.10.007.

85. Rawshani A, Rawshani A, Franzen S, et al. Risk factors, mortality, and cardiovascular outcomes in patients with type 2 diabetes. $\mathrm{N}$ Engl J Med. 2018;379(7):633-44. https://doi.org/10.1056/ NEJMoa1800256.

86. Diabetes Control and Complications Trial/Epidemiology of Diabetes Interventions and Complications Study Research Group. Intensive diabetes treatment and cardiovascular outcomes in type 1 diabetes: the DCCT/EDIC Study 30-year follow-up. Diabetes Care. 2016;39(5):686-93. https://doi.org/ 10.2337/dc15-1990.

87. Steineck I, Cederholm J, Eliasson B, et al. Insulin pump therapy, multiple daily injections, and cardiovascular mortality in 18,168 people with type 1 diabetes: observational study. BMJ. 2015;350:h3234. https://doi.org/10.1136/bmj.h3234.

88. Jamiolkowska M, Jamiolkowska I, Luczynski W, Tolwinska J, Bossowski A, Glowinska Olszewska B. Impact of real-time continuous glucose monitoring use on glucose variability and endothelial function in adolescents with type 1 diabetes: new technology-new possibility to decrease cardiovascular risk? J Diabetes Res. 2016;2016:4385312. https://doi.org/ $10.1155 / 2016 / 4385312$. 
89. Origin Trial Investigators, Mellbin LG, Ryden L, et al. Does hypoglycaemia increase the risk of cardiovascular events? A report from the ORIGIN trial. Eur Heart J. 2013;34(40):3137-44. https://doi.org/ 10.1093/eurheartj/eht332.

90. Pietri AO, Dunn FL, Grundy SM, Raskin P. The effect of continuous subcutaneous insulin infusion on very-low-density lipoprotein triglyceride metabolism in type I diabetes mellitus. Diabetes. 1983;32(1):75-81.

91. Tames FJ, Mackness MI, Arrol S, Laing I, Durrington PN. Non-enzymatic glycation of apolipoprotein B in the sera of diabetic and non-diabetic subjects. Atherosclerosis. 1992;93(3):237-44.

92. Ray KK, Seshasai SR, Wijesuriya S, et al. Effect of intensive control of glucose on cardiovascular outcomes and death in patients with diabetes mellitus: a meta-analysis of randomised controlled trials. Lancet. 2009;373(9677):1765-72. https://doi.org/ 10.1016/S0140-6736(09)60697-8.

93. Bebu I, Braffett BH, Pop-Busui $\mathrm{R}$, et al. The relationship of blood glucose with cardiovascular disease is mediated over time by traditional risk factors in type 1 diabetes: the DCCT/EDIC study. Diabetologia. 2017;60(10):2084-91. https://doi.org/10. 1007/s00125-017-4374-4.

94. Cholesterol Treatment Trialists Consortium, Baigent C, Blackwell L, et al. Efficacy and safety of more intensive lowering of LDL cholesterol: a metaanalysis of data from 170,000 participants in 26 randomised trials. Lancet. 2010;376(9753):1670-81. https://doi.org/10.1016/s0140-6736(10)61350-5.

95. Colhoun HM, Betteridge DJ, Durrington PN, et al. Primary prevention of cardiovascular disease with atorvastatin in type 2 diabetes in the Collaborative Atorvastatin Diabetes Study (CARDS): multicentre randomised placebo-controlled trial. Lancet. 2004;364(9435):685-96. https://doi.org/10.1016/ S0140-6736(04)16895-5.

96. Baigent C, Keech A, Kearney PM, et al. Efficacy and safety of cholesterol-lowering treatment: prospective meta-analysis of data from 90,056 participants in 14 randomised trials of statins. Lancet. 2005;366(9493):1267-78. https://doi.org/10.1016/ S0140-6736(05)67394-1.

97. Cholesterol Treatment Trialists Consortium, Kearney PM, Blackwell L, et al. Efficacy of cholesterollowering therapy in 18,686 people with diabetes in 14 randomised trials of statins: a meta-analysis. Lancet. 2008;371(9607):117-25. https://doi.org/10. 1016/s0140-6736(08)60104-x.

98. Collins R, Armitage J, Parish S, Sleigh P, Peto R, Heart Protection Study Collaborative Group. MRC/
BHF Heart Protection Study of cholesterol-lowering with simvastatin in 5963 people with diabetes: a randomised placebo-controlled trial. Lancet. 2003;361(9374):2005-16.

99. Hero C, Rawshani A, Svensson AM, et al. Association between use of lipid-lowering therapy and cardiovascular diseases and death in individuals with type 1 diabetes. Diabetes Care. 2016;39(6):996-1003. https://doi.org/10.2337/ dc15-2450.

100. NICE. Lipid modification: cardiovascular risk assessment and the modification of blood lipids for the primary and secondary prevention of cardiovascular disease. London: National Institute for Health and Clinical Excellence; 2014.

101. Cannon CP, Blazing MA, Braunwald E. Ezetimibe plus a statin after acute coronary syndromes. N Engl J Med. 2015;373(15):1476-7. https://doi.org/10. 1056/NEJMc1509363.

102. Leiter LA, Cariou B, Muller-Wieland D, et al. Efficacy and safety of alirocumab in insulin-treated individuals with type 1 or type 2 diabetes and high cardiovascular risk: the ODYSSEY DM-INSULIN randomized trial. Diabetes Obes Metab. 2017;19(12):1781-92. https://doi.org/10.1111/dom. 13114.

103. The ASCEND Study Collaborative Group. Effects of n-3 fatty acid supplements in diabetes mellitus. N Engl J Med. 2018;1:1. https://doi.org/10.1056/ nejmoa1804989.

104. Bhatt DL, Steg PG, Miller M, et al. Cardiovascular risk reduction with icosapent ethyl for hypertriglyceridemia. N Engl J Med. 2018. https://doi.org/ 10.1056/nejmoa1812792.

105. NICE. Type 1 diabetes in adults: diagnosis and management. London: National Institute for Health and Care Excellence; 2015.

106. Chronic Kidney Disease Prognosis Consortium, Matsushita K, van der Velde M, et al. Association of estimated glomerular filtration rate and albuminuria with all-cause and cardiovascular mortality in general population cohorts: a collaborative metaanalysis. Lancet. 2010;375(9731):2073-81. https:// doi.org/10.1016/s0140-6736(10)60674-5.

107. de Boer IH, Bangalore S, Benetos A, et al. Diabetes and hypertension: a position statement by the American Diabetes Association. Diabetes Care. 2017;40(9):1273-84. https://doi.org/10.2337/dci170026.

108. Piepoli MF, Hoes AW, Agewall S, et al. 2016 European guidelines on cardiovascular disease prevention in clinical practice: the Sixth Joint Task Force 
of the European Society of Cardiology and Other Societies on Cardiovascular Disease Prevention in Clinical Practice (constituted by representatives of 10 societies and by invited experts) developed with the special contribution of the European Association for Cardiovascular Prevention \& Rehabilitation (EACPR). Eur Heart J. 2016;37(29):2315-81. https:// doi.org/10.1093/eurheartj/ehw106.

109. Joint British Societies' Board. Joint British Societies' consensus recommendations for the prevention of cardiovascular disease (JBS3). Heart. 2014;100(Suppl 2):ii1-67. https://doi.org/10.1136/heartjnl-2014-30 5693.

110. Purnell JQ, Braffett BH, Zinman B, et al. Impact of excessive weight gain on cardiovascular outcomes in type 1 diabetes: results from the Diabetes Control and Complications Trial/Epidemiology of Diabetes Interventions and Complications (DCCT/EDIC) Study. Diabetes Care. 2017;40(12):1756-62. https:// doi.org/10.2337/dc16-2523.

111. Seeger JP, Thijssen DH, Noordam K, Cranen ME, Hopman MT, Nijhuis-van der Sanden MW. Exercise training improves physical fitness and vascular function in children with type 1 diabetes. Diabetes Obes Metab. 2011;13(4):382-4. https://doi.org/10. 1111/j.1463-1326.2011.01361.x.

112. Herbst A, Kordonouri O, Schwab KO, Schmidt F, Holl RW, Germany DPVIotGWGfPD. Impact of physical activity on cardiovascular risk factors in children with type 1 diabetes: a multicenter study of 23,251 patients. Diabetes Care. 2007;30(8): 2098-100. https://doi.org/10.2337/dc06-2636.

113. Ranjan A, Schmidt S, Damm-Frydenberg C, Holst JJ, Madsbad S, Norgaard K. Short-term effects of a low carbohydrate diet on glycaemic variables and cardiovascular risk markers in patients with type 1 diabetes: a randomized open-label crossover trial. Diabetes Obes Metab. 2017;19(10):1479-84. https:// doi.org/10.1111/dom.12953.

114. Schoenaker DA, Toeller M, Chaturvedi N, Fuller JH, Soedamah-Muthu SS, EPCS Group. Dietary saturated fat and fibre and risk of cardiovascular disease and all-cause mortality among type 1 diabetic patients: the EURODIAB Prospective Complications Study. Diabetologia. 2012;55(8):2132-41. https:// doi.org/10.1007/s00125-012-2550-0.

115. Ahola AJ, Saraheimo M, Freese R, et al. Association between adherence to dietary recommendations and high-sensitivity C-reactive protein level in type 1 diabetes. Diabetes Res Clin Pract. 2017;126:122-8. https://doi.org/10.1016/j.diabres.2017.02.012.

116. ASC Group. Effects of aspirin for primary prevention in persons with diabetes mellitus. $\mathrm{N}$ Engl J
Med. 2018;1:1. https://doi.org/10.1056/nejmoa180 4988.

117. Rawshani A, Rawshani A, Franzen S, et al. Range of risk factor levels: control, mortality, and cardiovascular outcomes in type 1 diabetes mellitus. Circulation. 2017;135(16):1522-31. https://doi.org/10. 1161/CIRCULATIONAHA.116.025961.

118. Petrie JR, Chaturvedi N, Ford I, et al. Cardiovascular and metabolic effects of metformin in patients with type 1 diabetes (REMOVAL): a double-blind, randomised, placebo-controlled trial. Lancet Diabetes Endocrinol. 2017;5(8):597-609. https://doi.org/10. 1016/S2213-8587(17)30194-8.

119. Mathieu C, Zinman B, Hemmingsson JU, et al. Efficacy and safety of liraglutide added to insulin treatment in type 1 diabetes: the ADJUNCT ONE treat-to-target randomized trial. Diabetes Care. 2016;39(10):1702-10. https://doi.org/10.2337/dc1 6-0691.

120. Ratner RE, Dickey R, Fineman M, et al. Amylin replacement with pramlintide as an adjunct to insulin therapy improves long-term glycaemic and weight control in type 1 diabetes mellitus: a 1-year, randomized controlled trial. Diabet Med. 2004;21(11):1204-12. https://doi.org/10.1111/j. 1464-5491.2004.01319.x.

121. Ceriello A, Piconi L, Quagliaro L, et al. Effects of pramlintide on postprandial glucose excursions and measures of oxidative stress in patients with type 1 diabetes. Diabetes Care. 2005;28(3):632-7.

122. Fattah H, Vallon V. The potential role of SGLT2 inhibitors in the treatment of type 1 diabetes mellitus. Drugs. 2018;78(7):717-26. https://doi.org/10. 1007/s40265-018-0901-y.

123. McCrimmon RJ, Henry RR. SGLT inhibitor adjunct therapy in type 1 diabetes. Diabetologia. 2018; 61(10):2126-33. https://doi.org/10.1007/s00125018-4671-6.

124. Yamada T, Shojima N, Noma H, Yamauchi T, Kadowaki T. Sodium-glucose co-transporter-2 inhibitors as add-on therapy to insulin for type 1 diabetes mellitus: systematic review and meta-analysis of randomized controlled trials. Diabetes Obes Metab. 2018;20(7):1755-61. https://doi.org/10.1111/dom. 13260.

125. Ridker PM, Everett BM, Thuren T, et al. Antiinflammatory therapy with canakinumab for atherosclerotic disease. N Engl J Med. 2017; 377(12):1119-31. https://doi.org/10.1056/NEJMoa 1707914. 